\title{
Pembiasaan Membaca dalam Pelajaran Bahasa Indonesia melalui Gerakan Literasi Sekolah
}

\author{
1Kartika Megantara
}

\section{${ }^{2}$ Abdul Wachid BS.}

\section{2Universitas Islam Negeri Prof. KH. Saifuddin Zuhri, Indonesia}

${ }^{1}$ kartikamegantara@yahoo.com

2abdulwachidbs@gmail.com

\begin{abstract}
Abstrak
Aktifitas membaca merupakan bagian dari kegiatan dalam dunia literasi. Literasi merupakan bagian integral dari dunia pendidikan dengan alasan bahwa informasi dan pengetahuan didapatkan melaui kegiatan membaca. Membaca adalah suatu ketrampilan yang dapat menjadi faktor penunjang dalam kemampuan berbahasa lainnya seperti berbicara dan juga menulis. Dalam kehidupan, membaca memiliki posisi yang sangat penting, utamanya di era informasi yang berkembang dengan sangat pesat sebagaimana keadaan yang dirasakan sekarang ini. Akan tetapi pada kenyataannya membaca belum menjadi sebuah kebiasaan di masyarakat Indonesia. Membaca masih hanya menjadi cara untuk mengisi waktu seggang. Maka tak berlebihan bila sebuah penelitian telah menunjukan sangat rendahnya kemampuan membaca pelajar di Indonesia. Hal haruslah menjadi tantangan bagi dunia pendidikan untuk sesegera mungkin memperbaikinya. Gerakan Literasi Sekolah merupakan bagian dari kegiatan Gerakan Literasi Nasional yang dicanangkan Pada tahun 2016, yang memiliki tujuan Menumbuh kembangkan budi pekerti siswa dengan pembudayaan ekosistem literasi sekolah yang diwujudkan dalam Gerakan Literasi Sekolah agar mereka menjadi pembelajar sepanjang hidupnya. Tujuan akhir dari penelitian ini adalah untuk menggambarkan dan menganalisa berbagai kegiatan yang terkait Gerakan Litersi Sekolah sebagai suatu upaya menumpuhkan kebiasaan membaca di MI Muhammadiyah Penaruban. Dalam proses penelitian ini peneliti memilih Jenis penelitian deskriptif kualitatif dimana dalam penelitian yang dilakukan peneliti menjeskan dan menguraikan hasil penelitian yang dilakukan mengacu pada data-data yang didapatkan. Berangkat dari data-data yang didapat melalui beberapa metode peneliti berkesimpulan bahwa kegiatan Gerakan Literasi Sekolah (GLS) di MI Muhammadiyah Penaruban Kabupaten Purbalingga berjalan dengan baik dan bermanfaat bagi siswa dalam menumbuhkan kebiasaan membaca sebagai salah satu bagian dari literasi. Beberapa kegiatan yang telah dilakukan dalam upaya pembiasaan membaca siswa antara lain : membuat pojok baca, menyadiakan waktu khusus untuk membaca, Memajang hasil karya siswa, Pengadaan buku bacaan siswa di Perpustakaan, Mengadakan kegiatan lomba literasi bagi siswa, Membuat majalah dinding, dan Kepala sekolah aktif dalam kegiatan literasi.
\end{abstract}

Kata Kunci : Kebiasaan, Membaca, Gerakan literasi sekolah. 


\section{Abstract}

Reading activities are part of activities in the world of literacy. Literacy is an integral part of the world of education because information and knowledge are obtained through reading activities. Reading is a skill that can be a supporting factor in other language skills such as speaking and writing. In life, reading has a very important position, especially in the information age which is growing very rapidly as it is today. However, in reality, reading has not become a habit in Indonesian society. Reading is still only a way to fill spare time. So it is no exaggeration if a study has shown the very low reading ability of students in Indonesia. This should be a challenge for the world of education to fix it as soon as possible. The School Literacy Movement is part of the activities of the National Literacy Movement launched in 2016, which has the aim of developing students' character by cultivating the school literacy ecosystem which is manifested in the School Literacy Movement so that they become learners throughout their lives. The final objective of this study is to describe and analyze various activities related to the School Literacy Movement as an effort to develop reading habits at MI Muhammadiyah Penaruban. In the process of this research, the researcher chose the type of qualitative descriptive research where the research conducted by the researcher explained and described the results of the research conducted referring to the data obtained. Based on the data obtained through several methods, the researchers concluded that the School Literacy Movement (GLS) activities at MI Muhammadiyah Penaruban Purbalingga Regency were going well and beneficial for students in developing reading habits as a part of literacy. Some of the activities that have been carried out to familiarize students with reading include: creating a reading corner, providing a special time for reading, displaying student work, procuring student reading books in the library, holding literacy competitions for students, making wall magazines, and active principals in literacy activities.

Keywords: Habits, Reading, School literacy movement

\section{Pendahuluan}

Aktifitas membaca merupakan bagian dari kegiatan dalam dunia literasi. Literasi merupakan bagian integral dari dunia pendidikan dengan alasan bahwa informasi dan pengetahuan didapatkan melaui kegiatan membaca. Berhasil atau gagalnya proses belajar mengajar dapat ditentukan dari salah satu faktor yaitu membaca (Faradina, 2017: 60). Agar siswa mampu mengenal, memahami, dan menerapkan ilmu yang telah diperoleh dari proses belajar mengajar dalam dunia pendidikan. Ketrampilan membaca merupakan kompetensi yang wajib dimiliki oleh siswa. Membaca adalah suatu ketrampilan yang dapat menjadi faktor penunjang dalam kemampuan berbahasa lainnya seperti berbicara dan juga menulis (Mansyur, 2018). Berangkat dari pemahaman tersebut dapat kita yakini bahwa pada dasarnya ketrampilan membaca haruslah dikuasai oleh siswa semenjak usia dini. Dalam kehidupan, membaca memiliki posisi yang sangat penting, utamanya di era informasi yang berkembang dengan sangat pesat sebagaimana keadaan yang dirasakan sekarang ini. Jalil Dan Elmustian (2006: 66) berpendapat membaca merupakan suatu kemampuan yang bermanfaat untuk mendapatkan berbagai informasi, pengetahuan, dan pengalaman baru, hal ini karena aktifitas membeca bersifat reseptif atau menerima. Pengatahuan dan informasi inilah yang akan menjadi pintu untuk membuka wawasan yang selanjutnya dapat merubah paradigma dalam berpikir dan bertindak seseorang menuju kemajuan. Bahkan dalam kitab suci al-Quran sendiri perintah untuk membaca menjadi ayat yang pertama kali diturunkan. 
Akan tetapi pada kenyataannya membaca belum menjadi sebuah kebiasaan di masyarakat Indonesia. Membaca belum menjadi sebuah aktifitas utama, membaca masih hanya menjadi cara untuk mengisi waktu seggang. Maka tak berlebihan bila sebuah penelitian telah menunjukan sangat rendahnya kemampuan membaca pelajar di Indonesia. Pada tanggal 3 Desember 2019, Hasil akhir penelitian Programme for International Student Assessment (PISA) yang dilakukan pada tahun 2018 telah diumumkan. Hasilnya dari penelitian yang dilakukan pada 600.000 orang anak yang berumur 15 tahun, diaman anak-anak tersebut berasal dari 79 Negara di dunia dengan melakukan pembandingan kemampuan membaca, kemampuan matematika, dan kinerja sains tersebut, Indonesia berada pada peringkat 74 pada kategori kemampuan membaca dengan skor rata-rata 371 (Tohir, 2019: 1). Fakta di atas tentunya sangat menyedihkan.

Rendahnya tingkat kemampuan membaca siswa di Indonesia haruslah menjadi tantangan bagi dunia pendidikan untuk sesegera mungkin memperbaikinya. Pada dasarnya pemerintah sebagai pengambil kebijakan telah berupaya untuk meningkatkan kemampuan membaca yang dikuasai siswa dengan melakukan gerakan literasi yang disebut Gerakan Literasi Sekolah disingkat GLS.

Gerakan Literasi Sekolah merupakan bagian dari kegiatan Gerakan Literasi Nasional yang dicanangkan Pada tahun 2016 oleh Kementerian Pendidikan dan Kebudayaan sebagai lembaga yang memilki kewenangan dalam bidang pendidikan. Program ini merupakan perwujudan dari peraturan menteri pendidikan dan Kebudayaan Nomor 23 Tahun 2015 tentang budi pekerti, yang memiliki tujuan menumbuh kembangkan budi pekerti siswa dengan pembudayaan ekosistem literasi sekolah yang diwujudkan dalam Gerakan Literasi Sekolah agar mereka menjadi pembelajar sepanjang hidupnya (Faizah dkk, 2016: 2).

Guru sebagai garda terdepan dalam dunia pendidikan disekolah harus mampu mengimplementasikan GLS. Guru harus menghadirkan kegiatan-kegiatan yang kreatif dan inovatif untuk mendorong, mengembangkan, dan menumbuhkan minta siswa dalam kemampuan membaca. Dengan kegiatan yang kreatif dan inovatif ini siswa diharapkan akan memiliki kemampuan membaca yang baik sehingga akan melahirkan generasigenerasi berbudaya membaca.

Tujuan akhir dari penelitian ini adalah untuk menggambarkan dan menganalisa berbagai kegiatan yang terkait Gerakan Litersi Sekolah sebagai suatu upaya menumpuhkan kebiasaan membaca di MI Muhammadiyah Penaruban.

Berangkat dari penjelasan di atas dapatlah diambil suatu kesimpulan bahwa MI Muhammadiyah Penaruban telah melakukan berbagai kegiatan yang termasuk dari GLS sebagai suatu upaya inovatif dan kreatif dalam menumbuhkan kebiasaan membaca bagi siswa.

\section{Kajian Teori}

Pembiasaan adalah suatu poses penanaman kebiasaan kepada anak dan merupakan salah satu cara mendidik anak (Sapendi, 2015 : 27). Sedangankan berdasarkan penelitian Marwiyati (2020: 154) pembiasaan adalah prilaku mempengaruhi seseorang yang dilakukan secara sadar, sistematis, dan berulang-ulang untuk menajadikan seseorang melakukuan sesuatu tanpa perlu dipengaruhi. 
Kebiasaan itu merupakan hasil dari prilaku yang dilakukan secara terencana, penuh kesadaran, sehingga orang yang dipengaruhi tadi terbiasa dengan apa yang dilakukan. Dengan pengertian yang lain pembiasaan adalah prilaku yang secara teratur dilakukan. Kebiasaan menadika orang melakukan sesuatu tanpa memperlukan pemikiran yang panjang.

Membaca merupakan bagian dari empat ranah ketrampilan berbahasa Indonesia yang meliputi Ketrampilan mendengar, keterampilan menyimak, keterampilan berbicara, dan ketrampilan menulis. Hal ini sesuai dengan amanat Undang-Undang No 2 Tahun 1989 tentang Sistem Pendidikan Nasional, menjelaskan salah satu ketrampilan yang haris dijaga, dirawat, dan dikembangkan adalah membaca.

Harjasujana (1996: 4) mempercayai bahwa membaca merupakan suatu proses. Membaca merupakan proses tunggal yang dibangun dari sintesa berbagai proses yang menyatu. Membaca dapat dipahami sebagai aktifitas pelafalan kata-kata, memahami kata, dan menemukan makna sebuah bacaan.

Gerakan literasi sekolah atau GLS adalah salah suatu upaya menjadikan siswa memiliki budaya membaca dan menulis sebagai langkah untuk menjadikan pembelajaran sebagai aktifitas sepanjang hidup. Gerakan didicetuskan oleh Kemendikbud. Dalam GLS salah satu mendapatkan sorotan utama adalah buku, buku sebagai sumber informasi dan ilmu pengetahuan adalah salah satu komponen yang melekat erat dalam dunia pendidikan. Salah satu komponen yang tidak dapat dilepaskan dari ranah pendidikan adalah buku Jorge Luis Borges (Laksono, dkk, 2016:7).

\section{Metode penelitian}

Jenis Penelitian deskriptif kualitatif dimana dalam penelitian yang dilakukan peneliti menjeskan dan menguraikan hasil penelitian yang dilakukan mengacu pada datadata yang didapatkan.

Pengambilan data pada penelitian ini dilakukan melalui wawancara, observasi, dan dokumentasi. Metode observasi atau pengamatan dilakukan dengan pengamatan tentang pelaksanaan gerakan literasi sekolah di MI Muhammadiyah Penaruban. Adapun wawancara dalam penelitian ini, peneliti mengumpulkan informasi atau data dengan memberikan pertanyatan-pertanyaan yang telah dirancang dengan sistematis, mengacu pada tujuan penelitian, yang dilakukan secara langsung baik kepada responden yang relevansi dengan penelitian yang dilakukan maupun tenaga ahli yang memiliki kompetensi dan tanggung jawab dalam suatu masalah atau bidang.

Analisis model interaktif merupakan model analisis yang digunakan peneltian ini. Reduksi data, sajian, data dan penarikan simpulan merupakan komponen analisis yang dilakukan secara interaktif dengan aktifitas mengumpulkan data sebagai suatu lingkaran siklus. 


\section{Hasil dan Pembahasan}

Berdasarkan wawancara dengan kepala MIM Penaruban Nur Laily didapatkan informasi bahwa MIM Penaruban telah melakukan beberapa upaya untuk meningkatkan kebiasaan membaca siswa sebagai bagian dari kegiatan literasi di madrasahnya. Hal tersebut dilakukan agar literasi terutama kebiasaan membaca dan menulis di MIM Penaruban menjadi sebuah budaya sekaligus mendukung proses pembelajaran siswa khususnya pelajaran Bahasa Indonesia. Usaha yang dilakukan antara lain :

\section{Pembuatan Pojok Baca}

Berdasarkan pengamatan dan wawancara dengan guru diperoleh informasi bahwa MIM Penaruban membuat pojok baca di setiap ruang kelas. Di pojok baca tersebut disediakan beberapa buku bacaan dengan tema yang bervariasi seperti dongeng cerita rakyat, seri ilmu pengetahuan, agama, ensiklopedi dan lainnya. Pembuatan pojok baca di tiap kelas ini memiliki tujuan agar siswa mudah untuk mengakses buku-buku bacaan untuk dibaca.

Pojok baca di MIM Penaruban dibuat dengan penuh kreatifitas dan dibuat sangat menarik. Pojok baca dibuat dengan tema tertentu yang berbeda pada setiap pojok baca, dengan cat yang berwarna-warni dan hiasan-hiasan serta pemberian ornamen menjadikannya benar-benar menarik perhatian. Hal ini dilakukan agar siswa semakin tertarik serta senang dan nyaman dalam memanfaatkan pojok baca tersebut.

\section{Waktu Khusus Membaca}

Mengacu dari informasi yang dilakukan melalui wawancara dengan kepala madrasah diperoleh informasi bahwa setiap hari sebelum memulai proses pembelajaran diharuskan bagi setiap siswa untuk membaca buku bacaan atau pengayaan selama 15 menit. Kegiatan ini dipantau oleh guru tiap kelas. Pada kegiatan ini siswa dapat memanfaatkan pojok baca yang disediakan di setiap kelas atau dapat pula membawa buku sendiri.

Tujuan yang ingin didapatkan dari kegiatan ini agar para siswa memiliki kebiasaan dalam membaca serta menambah pengetahuan sehingga mendukung proses belajar mengajar.

\section{Memajang Hasil Karya Siswa}

Berdasarkan pengamatan terlihat beberapa karya siswa terkait dengan kegiatan literasi baik berupa poster motivasi dan media pembelajaran tertempel di dindingdinding kelas, serta beberapa tempat yang lainya yang disediakan khusus oleh madrasah. Menurut gois hal ini dilakukan sebagai upaya mengapresiasi hasil karya siswa serta untuk menciptakan lingkungan yang dapat memotivasi siswa untuk berkarya.

\section{Pengadaan Buku Bacaan siswa di Perpustakaan}

Berdasarkan wawancara dengan kepala madrasah dan pengelola perpustakaan, MIM Penaruban memiliki koleksi buku sebayak 2543 eksemplar buku. Bila dibandingkan dengan jumlah siswa sebanyak 265 siswa maka jumlah buku yang tersedia masih 
dikategorikan kurang. Hal berakibat siswa kurang tertarik untuk datang dan membaca buku diperpustakaan. Selain itu belum tersedianya ruang perpustakan yang representative baik dari segi ukuran maupuan fasilitas menjadikan kegiatan membaca di perpustakaan kurang nyaman.

Guna menyelesaikan persolan yang ada maka kepala madarash melakukan beberapa upaya. Pertama berupaya unutk menambah koleksi buku bacaan siswa. MIM Penaruban melakuan beberapa upaya untuk menambah koleksi buku bacaan bagi siswa yaitu : Pertama. Setiap tahun kepala madrasah menganggarkan pembelian buku bacaan melalui dan Bantuan Operasional Sekolah atau BOS akan tetapi persentase jumlah dana yang dianggarkan masih sedikit belum sesuai dengan atauran yang ada yaitu $10 \%$ hal ini disebabkan. Kedua. Bantuan Pihak ketiga MIM Penaruban juga meminta bantuan dalam bentuk proposal guna pengadaan buku-buku bacaan sisa baik ke Perpusatakaan Nasional, Perpusatakaan Propinsi, maupun beberapa perusahaan yang beroprasi di sekitar sekolah.

\section{Mengadakan Kegiatan Lomba Literasi bagi Siswa}

Kegiatan lomba literasi sangat penting. Kegiatan lomba dapat merangsang anak untuk belajar, dan berkompetisi, kegiatan lomba juga dapat memberi motivasi serta member ruang apresiasi.

Diantara Beberapa contoh lomba berbasis literasi yang diadakan di MIM Penaruban antara lain antara lain: Lomba membaca puisi, lomba mendongeng, lomba mading, lomba membuat poster, dan lomba teks proklamasi. Para siswa sangat antusias mengikuti perlombaan apalagi dengan adanya hadiah atau piala menambah semangat siswa untuk mengikutinya.

\section{Membuat Majalah Dinding}

Bagi siswa kelas IV sampai dengan kelas VI MIM penaruban menyelenggaraan kegiatan pembuatan majalah dinding yang dibina dan dipandu oleh wali kelas masingmasing. Konten-konten yang ditampilkan merupakanhasil karya darai para siswa.

Dengan adanya majalah dinding ini siswa-siswi MIM Penaruban yang dibuat dengan menarik menadikan para siswa tertarik untuk membacanya beberapa konten yang ditampilkan antara lain : dongeng anak, pengetahuan singkat, bacaan al-Quran atau hadits, poster, puisi, biografi tokoh, dan lain-lain.

\section{Kepala Sekolah Aktif dalam Kegiatan Literasi}

Kepala MIM Penaruban juga sangat aktif dalam kegiatan literasi. Siti Nuralaleli telah menghasilan beberapa karya buku baik merupakan karya sendiri maupun karya bersama dengan penulis lain, diantara judul buku yang berhasil diterbitkan antara lain : Cerita Bocah Klawing, 41 Hari Bersama Suami \& Bunda di Rumah-Mu, Meraki Asa, Antologi Puisi Khazanah Pendidikan Indonesia Jilid 1sampai 4, Senandika Pena, Guratan Pena, Kenangan Bersamamu, Menyulam Rindu dalam Rintik Hujan, Kasih Guru Tak Terbilang, Warna Kasih Ibu, Impresif, serta beberapa buku yang belum diterbitkan. Ia juga menerima beberapa penghargaan terkait kegiatan kepenulisan antara lain : Piagam Biru, Perak, Emas, Platinum, dan Diamond dari Gurusiana serta beberapa penghargaan tingkat nasional. 
Selain itu ia juga aktif dalam organisasi kepenulisan seperti di Mediaguru dan aktif menuliskan karya-karyanya dalam blog Mediaguru.

\section{Simpulan}

Berangkat dari data-data yang didapat melalui beberapa metode peneliti berkesimpulan bahwa kegiatan Gerakan Literasi Sekolah (GLS) di MI Muhammadiyah Penaruban Kabupaten Purbalingga berjalan dengan baik dan bermanfaat bagi siswa dalam menumbuhkan kebiasaan membaca sebagai salah satu bagian dari literasi.

Pada pelaksanaan GLS seluruh komponen pendidikan siswa, guru, dan pustakawan saling mendukung dan memberikan peran aktif dalam setiap kegiatan GLS yang diselenggarakan. Beberapa kegiatan yang telah dilakukan antara lain : membuat pojok baca, menyadiakan waktu khusus untuk membaca, Memajang hasil karya siswa, Pengadaan buku bacaan siswa di Perpustakaan, Mengadakan kegiatan lomba literasi bagi siswa, Membuat majalah dinding, dan Kepala sekolah aktif dalam kegiatan literasi

Simpulan di atas menjadi bahan refleksi untuk memberikan saran Sebaiknya kegiatan-kegiatan yang merupakan bagian dari GLS Diprogramkan dengan mengoptimalkan potensi dan sumber daya yang ada pada tiap-tiap sekolah. Selanjutnya sangat penting pula untuk mendorong peran aktif seluruh komponen pendidikan di sekolah dan GLS dapat dilaksanakan secara lebih luas di sekolah-sekolah yang ada di Indonesia.

\section{Ucapan Terima Kasih}




\section{Daftar Pustaka}

Dimas, Muhammad Rasyid. (2005). 25 Kiat Mempengaruhi Jiwa Dan Akal Anak. Bandung: Syamil Cipta Media.

Faizah, Dewi Utama, dkk (2016). Panduan Gerakan Literasi Sekolah di Sekolah Dasar. Jakarta: Direktorat Pembinaan Sekolah Dasar Direktorat Jendral Pendidikan Dasar dan Menengah Kementerian Pendidikan dan Kebudayaan.

Faradina, Nindya. (2017).Pengaruh Program Gerakan Literasi Sekolah terhadap Minat Baca Siswa di SD Islam Terpadu Muhammadiyah An-Najah Jatinom Klaten. Jurnal Hanata Widya, 6(8), 60-69. (Diakses pada 17 Juni 2021).

Harjasujana, A.S. \& Damaianti, V.S. (2003). Membaca dalam Teori dan Praktik. Bandung: Mutiara.

Jalil, Abdul Dan Elmustian. (2020). Pendidikan Bahasa Indonesia Di Kelas-Kelas Rendah Sekolah Dasar. Pekanbaru: Unri Press.

Laksono, Kisyani dkk. (2016). Manual Pendukung Gerakan Literasi sekolah Untuk Jenjang Sekolah Menengah Pertama. Jakarta: Kementerian Pendidikan dan Kebudayaan Sekolah Menengah Pertama.

Mansyur, Umar.(2018).Korelasi Minat Baca dengan Kemampuan Menulis Karya Tulis Ilmiah Mahasiswa Pendidikan Bahasa Indonesia UMI. Multilingual: Jurnal Kebahasaan Dan Kesastraan, 17(1) , 11-22. (Diakses pada 17 Juni 2021).

Marwiyati, Sri. (2020). Penanaman Pendidikan Karakter Melalui Pembiasaan. Jurnal ThufuLA, 9(2), 152-163. (Diakses pada 8 Juli 2021)

Sapendi. (2015). Internalisasi Nilai-nilai Moral Agama Pada Anak Usia Dini, At-Turats, 9 (2), 17-35. (Diakses pada 8 Juli 2021)

Tohir, Mohammad. (2019). Hasil PISA Indonesia Tahun 2018 Turun Dibanding Tahun 2015. Tersedia Online: https://matematohir.wordpress.com/2019/12/03/hasilpisa-indonesiaTahun -2018-turun-dibanding-tahun-2015/ [03 Desember 2019] 